\title{
A Difícil Institucionalização da Ciência Política Italiana: De Muratori a Mussolini
}

\author{
Alvaro Bianchi \\ Universidade Estadual de Campinas (Unicamp), Campinas, SP, Brasil. E-mail: \\ albianchi@terra.com.br
}

$\mathrm{O}$ s cientistas políticos estão acostumados à ideia de que foi nos Estados Unidos que sua ciência adquiriu contornos precisos e se constituiu em uma disciplina acadêmica. Habituados a pensar desse modo, pesquisadores têm descurado o estudo de diferentes tradições nacionais do pensamento político e de suas diversas trajetórias de constituição disciplinar. A investigação das diferentes tradições e trajetórias nacionais de institucionalização da Ciência Política poderia fornecer um quadro mais rico e multifacetado de sua história disciplinar, permitindo um conhecimento mais rigoroso não apenas dos obstáculos que ela enfrentou, como também das alternativas disponíveis. Em contextos nacionais como o brasileiro, nos quais a institucionalização da Ciência Política é ainda relativamente recente, esse conhecimento poderia contribuir para uma visão mais complexa e plural do campo da disciplina.

Recolhendo uma rica tradição nacional de pensamento político e, particularmente, os frutos deixados pelo realismo maquiaveliano, a ciência política italiana debruçou-se, em seus primeiros anos, sobre a complexa experiência de afirmação de um Estado liberal e nacional, fruto do processo de unificação italiana. Gaetano Mosca (1858-1941) e Vilfredo Pareto (1848-1923) foram seus precursores, mas não ficaram sós e foram seguidos por autores como Giuseppe Carle (1845-1917),

DADOS - Revista de Ciências Sociais, Rio de Janeiro, vol. 60, n³, 2017, pp. 793 a 823. 
Benedetto Croce (1866-1952), Giole Solari (1872-1952), Giovanni Gentile (1875-1944), Robert Michels (1876-1936), Giovanni Amendola (1882-1926), Antonio Gramsci (1891-1937), Guido Dorso (1892-1947), Carlo Rosselli (1899-1937) e Piero Gobetti (1901-1926)ํ.

Termos como ciências políticas, estudos políticos, ciência da política, ciência do Estado, ciência político-administrativa e ciência política, eram correntes na Itália desde o início do século XVIII e foram lugar comum no século XIX. As origens desse léxico e a tradição que lhe dá sentido remetem a Niccolò Machiavelli (1469-1527) e a Giambattista Vico (1668-1744). De Machiavelli pode-se dizer que, embora não tenha advogado explicitamente em favor de uma ciência, assentou suas bases ao separar a reflexão sobre a política da teologia e da moral. Vico, por sua vez, foi além e definiu de modo preciso a "ciência política, que não é, senão, a ciência de comandar e obedecer na cidade" (2005:728; tradução livre).

Contraditoriamente, a existência de uma forte tradição de pensamento político não tornou mais fácil a afirmação dessa ciência como uma disciplina acadêmica independente. Já no final do século XVIII atribuía-se à Ciência Política na península italiana a missão de formar os quadros dirigentes - políticos e administrativos - do novo Estado nacional. Logo surgiram as primeiras tentativas de afirmação dessa ciência como um campo ou uma divisão dos estudos jurídicos. Mas, ao contrário do que se poderia esperar, a ciência política só se tornaria uma disciplina autônoma e institucionalizada no século XX, após a Segunda Guerra Mundial.

Este artigo investiga os obstáculos que essa ciência enfrentou em seu processo de institucionalização. Tais obstáculos não poderiam ser revelados se a investigação se limitasse a perquirir as grandes obras dos grandes autores. Uma história interna da disciplina também não obteria melhores resultados. Uma melhor compreensão do difícil processo de institucionalização da Ciência Política pode ser obtida tornando a história das ideias e a história da disciplina objetos de uma história política. Esse procedimento, que aqui se chama de uma história política da Ciência Política, pressupõe a reconstrução do contexto político no qual essa ciência tem lugar e dos conflitos que nele ocorrem. Para levar a cabo essa história é preciso diversificar as fontes documentais e utilizar registros pouco comuns na história da Ciência Política, recorrendo não apenas aos autores mais conhecidos, como também àqueles meno- 
res, mas ainda assim institucionalmente relevantes, à imprensa da época e à legislação.

O argumento principal deste artigo é que a forte associação da Ciência Política com o processo de construção do Estado nacional e com o ensino do direito foram as causas principais de sua lenta institucionalização. A primeira seção apresenta os primeiros acenos à constituição de uma academia para o estudo das regras do bom governo, feitos por Antonio Muratori em meados do século XVIII, e as iniciativas que tiveram lugar com a ocupação napoleônica e a emergência das repúblicas jacobinas na Itália. A segunda reconstrói as diversas iniciativas legislativas que foram tomadas, após a constituição do novo Reino da Itália, com vistas à criação de faculdades, escolas e cursos de ciências políticas, destinados a formar o pessoal dirigente do novo Estado nacional, bem como os debates que essas iniciativas provocaram. A terceira seção expõe o conturbado processo de fascistização das ciências políticas que tem lugar a partir de 1923, culminando com a criação da Facoltà Fascista di Scienze Politiche, na Università di Perugia. Na seção conclusiva, exploram-se as razões do fracasso dessas iniciativas.

\section{DO ISTITUTO NAZIONALE ÀS FACOLTÁ DI SCIENZE POLITICHE}

As primeiras iniciativas institucionais com vistas a fomentar e organizar o estudo da política ocorreram na Itália durante o período napoleônico. Em 1798, foi fundado o Istituto Nazionale della Reppublica Romana, por iniciativa do matemático Gaspar Monge, criador da École Polytechnique. O Istituto encontrava-se fortemente inspirado no modelo francês e dividia-se em duas classes - "Ciências matemáticas e físicas" e "Filosofia, literatura e belas artes" -, cada uma das quais abrangia seis divisões e uma delas era dedicada às scienze politiche (cf. Pepe, 1996:711). No mesmo sentido, logo após a transformação da Repubblica Cisalpina em Repubblica Italiana, foi fundado o Istituto Nazionale, por decreto legislativo de 17 de agosto de 1802. Também inspirado no modelo francês, o Istituto dividia-se em três seções, uma das quais dedicadas às "scienze morali e politiche" (Bollettino, 1803:254)2.

A partir da década de 1840, tornou-se comum a referência às scienze e legge politiche, nome da cátedra da Università di Padova ocupada por Cristoforo Negri em 1843, ou mesmo às scienze politiche, como no Discorso intorno al governo costituzionale per istruzione di quelli che non sono versati nelle scienze politiche, de Paolo Costa (1831). No singular, 
a expressão "scienza politica" era menos frequente, mas foi citada, por exemplo, na tradução italiana do livro de Carl Ludwig Von Haller, Ristaurazione della scienza politica, ovvero Teoria dello stato naturale sociale opposta alla supposizione di uno stato civile fattizio, de 1828, e na obra de Filippo Scolari, Massime fondamentali di scienza politica offerte per necessaria e pronta istruzione del popolo della Repubblica di Venezia al cittadino ministro Angelo Toffoli, de 1848. A expressão ganhou força na segunda metade do século XIX e projetou-se na cultura política da Itália postrisorgimentale, destacando-se no importante e muito difundido texto de Saverio Scolari, Istituzioni di scienza política, publicado em 1874.

A consolidação da ciência política como uma disciplina acadêmica foi, entretanto, muito mais difícil do que se poderia imaginar. Os acenos favoráveis à constituição de uma academia voltada para o estudo do governo já podem ser encontrados no século XVIII, particularmente na obra do sacerdote modenense Antonio Muratori (1672-1750). Em “Della Pubblica Felicità", ensaio escrito em seus últimos anos de vida, era clara a direção política do argumento e seu impulso reformista (cf. Muratori, 1749). Muratori expressava uma nova experiência política que se processava na Itália, uma experiência na qual, embora a unidade estatal e social não tivesse ainda lugar, já era possível encontrar uma unidade cultural que se manifestava na literatura, nas academias e nos primeiros jornais em circulação na península (cf. Albertoni, 1985:198).

Em um contexto no qual a autodeterminação, a autonomia e o autogoverno começavam a reaparecer no pensamento político, Muratori julgou necessário inscrever, em um conjunto de diretrizes destinadas a orientar o bom governo, um programa para a educação da juventude e para a formação de governantes ${ }^{3}$. Depois de discorrer sobre o bom governo e os bons ministros, o reformador modenense concluiu afirmando que os bons ministros, ou seja, aqueles dotados de todas as prerrogativas necessárias para o manejo adequado da justiça, da economia e da política, não nasciam em plantas (Muratori, 1749:32-33). Caberia, assim, ao príncipe incitar a juventude a entrar nas carreiras de governo (idem:34). Um importante meio para tanto seria a criação de "uma Academia específica, na qual se estudassem as regras do sábio governo do Povo, ofício tão importante quanto difícil" (idem:42; tradução livre).

Em tal academia seria possível uma educação particular que reconhecesse os engenhos mais competentes e adaptados ao "pubblico Ministero" (idem:37). Para dar conta das exigências dessa atividade, a acade- 
mia deveria ensinar a filosofia moral, a jurisprudência justiniana e o Gius Pubblico, a história antiga e moderna, a geografia, bem como estudar "os vários interesses dos Dominantes, os Costumes bons ou maus das várias Nações, as bem reguladas Máximas concernentes ao Comércio, ao Abastecimento, às Moedas, os Tributos etc., todos os assuntos que estão sob a inspeção de um Conselheiro de Estado" (idem:45). A estes ensinamentos teóricos deveriam, ainda, acrescentar-se aqueles provenientes da prática e da experiência, de modo a obter uma aprendizagem abrangente das coisas do governo (idem:45-46).

Mais de oitenta anos depois, em uma situação muito diversa, marcada pela experiência napoleônica e pela emergência e rápido fracasso das repúblicas jacobinas na Itália, o pensamento político da península encontrou uma forma de síntese na "civile filosofia" de Giandomenico Romagnosi (1761-1835), para o qual, a pesquisa sobre as leis da natureza humana seria, ao mesmo tempo, a base da moral, do direito e da política. A unidade sistemática entre essas diferentes formas da atividade humana deveria ser objeto, assim, de uma disciplina que se constituiria em uma verdadeira ciência política (cf. Albertoni, 1985:253). O empreendimento romagnosiano era orientado por um patriótico sentimento de independência nacional, que se tornava cada vez mais forte entre a burguesia e mesmo na aristocracia modernizadora do Norte da Itália. Sua pesquisa estava, por esse motivo, dirigida à investigação de uma forma estatal autônoma na qual a liberdade pudesse ter lugar.

A partir de 1808, Romagnosi passou a lecionar "alta legislação em sua relação com a administração pública" nas scuole speciali politico-legali, que promoveu e organizou em Milão. Os invasores austríacos consideraram que esse curso era um foco de sedição e difusão das ideias liberais, apesar do espírito moderado e aristocrático do professor, e o encerraram em $1817^{4}$. Antevendo o fechamento do curso, Romagnosi trabalhou febrilmente na composição dos Principj Fondamentali di diritto Amministrativo Onde Tesserne le Instituzioni, obra publicada em 1814 e na qual pretendia registrar suas lições para as futuras gerações de estudantes. Nos Principj, o professor milanês deixava claro que o sujeito que reuniria toda a doutrina da administração seria o "estado político", o qual deveria ser compreendido como uma "pessoa moral" (Romagnosi, 1839:43). Suas lições sobre o direito administrativo eram, assim, um curso sobre esse "estado político", sobre a doutrina do Estado. 
O curso pretendia-se abrangente e completo. Romagnosi distinguia as relações externas e internas das quais o Estado participava e que deveriam ser objeto de estudo. As relações externas diziam respeito à administração e custódia das fronteiras, à introdução de coisas e pessoas provenientes do exterior, e outras relações que em conjunto com as citadas apenas indiretamente deveriam tratar da doutrina. Romagnosi deu pouca atenção a essas relações externas e atribuiu primazia às que diziam respeito à vida interna daquela pessoa moral. Nas relações internas deveriam distinguir-se os assuntos civis, os assuntos cívicos, que compreenderiam a administração econômica, moral e tutelar, e os assuntos internos de Estado, os quais diriam respeito

ao complexo de leis fundadas sobre as relações reais das coisas para conservar e harmonizar as diversas partes do Estado tomadas em seu conjunto, em relação ao fim único e comum da formação e conservação dos corpos políticos contemplados em sua unidade individual (idem:63).

Era nesta última dimensão que se concentrava o estudo e a investigação da organização, conservação, economia, moral, tutela e reforma do Estado (idem:63-66).

Embora o programa de ensino e pesquisa fosse extremamente abrangente, é óbvio que não escapava aos limites dos estudos jurídicos próprios da época. A reflexão de Romagnosi articulava-se em torno do direito administrativo e não da política administrativa do Estado. Nos Principi, a política só tomava corpo na medida em que era objeto do direito. O próprio Romagnosi parecia consciente dos limites desse programa e, mais tarde, em sua obra Dell'Indole e dei Fattori dell Inicivilimento con Esempio del suo Risorgimento in Italia, de 1832, ponto alto de sua reflexão histórica-filosófica, expôs um novo plano de trabalho, afirmando que o estudo da jurisprudência deveria ser completado pela investigação do "direito natural público e das gentes, da economia civil, da estatística, da administração e da política de Estado" (Romagnosi, 1832:245).

A ciência encarregada de levar a cabo essa pesquisa não havia sido senão esboçada. Aquilo que Romagnosi denominava de scienze della cosa sociale, scienze della cosa pubblica, ou simplesmente scienze sociale, era um ramo da filosofia, o qual acompanhava o estudo do "homem interior" com o conhecimento "das exigências sociais dos lugares e dos tempos" (ibidem:246). Tratava-se de um empreendimento intelectual 
fortemente orientado por propósitos práticos, uma vez que caberia a essa ciência "mostrar como entre os entes se obtêm, mediante o ordenamento e a administração, a paz, a potência e a segurança, o que exige a moderação e a equidade" (idem). Os propósitos eram práticos, mas a pesquisa ainda era organizada de modo filosoficamente abstrato e juridicamente formalista, de maneira que esse empreendimento parecia não encontrar um lugar próprio em uma forma de conhecimento específica.

Outra pareceria ser, entretanto, a proposta feita por Romagnosi em uma obra publicada postumamente, La Scienza delle Costituzioni (1850). Nela, seu autor retomou o projeto platônico de constituição de um corpo acadêmico responsável pelo estudo e perpetuação da ciência do Estado e propôs "estabelecer, no centro da sociedade, um corpo permanente de instrução política, no qual, à guisa do templo de Vesta, fosse perpetuamente custodiado o depósito dos dogmas políticos" (Romagnosi, 1850:110). A proposta ia além daquela já levada a cabo no Istituto Nazionale, criado no início do século, logo após a proclamação da Repubblica Italiana. Sua intenção era a de fomentar a criação de um Istituto Politico, "para preparar os depositários e cultores das doutrinas e os funcionários da legislação, da administração do patrocínio público e da educação popular" (ibidem:111).

\section{ENTRE O DIREITO E A ADMINISTRAÇÃO PÚBLICA}

Apesar dos esforços de autores como Muratori e Romagnosi, entre os séculos XVIII e XIX, a Ciência Política e a ciência da administração pública eram vistas na Itália, preponderantemente, como desenvolvimentos práticos dos estudos jurídicos ou filosóficos. Os modelos que inspiravam os italianos eram dois: o alemão e o francês. Na Alemanha, os estudos políticos eram, geralmente, considerados um campo da reflexão filosófica e, portanto, se encontravam aninhados nas faculdades de filosofia, nas quais os estudantes podiam frequentar um grande número de cursos livres e concentrar seus esforços nas áreas prediletas, sem seguir um currículo fixo. Na França, o lugar desses estudos políticos era nas escolas de direito e os currículos eram bastante rígidos, organizados em torno de um grande número de disciplinas obrigatórias que não davam aos alunos margem de escolha (cf. Villari, 1902:404-405). Apesar da influência crescente das ideias provenientes da Alemanha, o modelo adotado na Itália seguiu o francês, localizando os estudos políticos e administrativos no interior das faculdades jurí- 
dicas e organizando as disciplinas em um currículo fixo que deveria ser cursado por todos os alunos.

A insatisfação na Itália com esse modelo era notável e, à medida que ganhava corpo a ideia de independência e unidade nacional, crescia o número daqueles que consideravam, assim como Muratori um século antes, que era necessário criar uma escola que fosse capaz de formar os futuros governantes. Com a constituição do novo Reino da Itália, em 1861, essa necessidade tornou-se premente. A reforma universitária liderada por Carlo Matteucci (1811-1868), em 1862, atendeu às crescentes demandas, criando-se uma Facoltà politico-administrativa ao lado das já existentes facoltá giuridiche. A iniciativa, entretanto, não perdurou. De acordo com a nova legislação, depois de quatro anos de estudo, os estudantes das faculdades político-administrativas poderiam obter um título que lhes permitia prestar os exames para os ofícios da administração pública, os consulados e embaixadas. Com os mesmos quatro anos, os estudantes de direito obteriam um diploma que lhes permitiria exercer a profissão de advogado ou a magistratura, além de disputar todos aqueles postos aos quais podiam se candidatar os alunos das faculdades político-administrativas. A vantagem cabia, assim, àqueles que tendo cursado uma facoltá giuridica tinham uma dupla habilitação, o que lhes abria tanto a carreira pública como a advocacia. Com uma estreita perspectiva profissional, não é de se estranhar que o número de inscritos nas Facoltà politico-administrative fosse muito pequeno e que três anos depois estas fossem dissolvidas ${ }^{5}$.

A proposta de criação de um curso autônomo de estudos políticoadministrativos foi retomada em 1869 por Angelo Messedaglia (1820-1901), no relatório sobre a instrução pública que apresentou naquele ano ao Senado. Segundo afirmava, a reunificação dos diplomas levada a cabo em 1865 não havia considerado "a índole particular e as várias proporções da cultura requeridas especificamente pelo político e pelo administrador" (Messedaglia, 1869:590). O argumento do senador era análogo àquele apresentado por Romagnosi mais de trinta anos antes. O direito prescreveria a retidão jurídica da ação, mas para o político e o administrador o importante seria a efficacia utile dos atos e não o dever ser (idem). As diferentes funções do direito e da políticaadministração faziam com que fosse necessário um ordenamento acadêmico diverso.

Foram necessários mais alguns anos para que Messedaglia visse sua proposta realizar-se de algum modo. Em 1875, o ministro da educação 
Ruggiero Bonghi (1826-1895) apresentou um novo regulamento para a Facoltà di Giurisprudenza, no qual estava prevista a criação, no âmbito desta, de cursos especiais para o estudo das scienze politiche, tais como "Enciclopédia das ciências políticas. Ciência da administração e saúde pública. Ciência das finanças. Contabilidade do Estado. Diplomacia e história dos tratados" (Bonghi, 1875:7078). Para estudar a implantação de tais cursos foi criada uma comissão de professores, coordenada pelo próprio Messedaglia, mas a crise parlamentar de 1876, que culminou com a queda do governo da Destra storica, interrompeu abruptamente os trabalhos daquele grupo de docentes.

A ideia só foi retomada em 1878, por intermédio do crítico literário Francesco De Sanctis (1817-1883), agora ministro da Instrução Pública. A proposta do ministro visava a criação de cursos especiais, nos quais teria lugar o ensino político-administrativo. Tais cursos comporiam uma verdadeira Scuola economico-administrativa, anexa à Facoltá di giurisprudenza (Messedaglia, 1880:20). Angelo Messadaglia, também professor de estatística na Facoltà giuridica de Roma, assumiu a direção da escola. Também passaram a fazer parte do corpo docente, Francesco Protonotari (1836-1888), professor de economia política; Giuseppe Saredo (1832-1902), de ciência da administração; Luigi Palma (1837-1899), de história e comparação das constituições modernas; e Antonio Salandra (1853-1931), de legislação econômica e financeira, todos docentes da Facoltà .

Um decreto de setembro de 1879 tornou mais claros os objetivos desses cursos e seu desenho institucional, transformando a Scuola em um corso complementare di scienze economico-administrative, sediado na Facoltà. Em seu discurso inaugural de 3 de dezembro 1879, o diretor Messedaglia apresentou o programa desse curso especial: ciência da administração, que foi concebida como fazendo parte, ao mesmo tempo, da economia política aplicada e das ciências do Estado; ciência das finanças; contabilidade do Estado; diplomacia e história diplomática (Messedaglia, 1880:22-25). A solução adotada colocava a universidade italiana a meio caminho entre o modelo francês e o alemão. Por um lado, mantinha o ensino da política e da administração pública vinculado aos cursos de direito, como na França. Mas, por outro, adotava aspectos das universidades prussianas, como os cursos livres, que davam mais autonomia para os estudantes escolherem as disciplinas de suas preferências. Criavam-se, assim, as condições para promover 
uma formação específica para a alta direção estatal, a cujos cargos os portadores de um título de estudos jurídicos poderiam se candidatar.

As idas e vindas dos diferentes projetos, propostas e regulamentos não escondem a intenção de seus proponentes. Tratava-se, antes de tudo, de formar técnicos, administradores e homens de Estado capazes de se encarregar da organização da vida política do Reino, uma ideia que já estava presente em Romagnosi. A Itália unificada carecia de pessoal de Estado com o necessário treinamento. Não apenas a política interna necessitava de funcionários em condições de fazer frente ao desafio da construção de uma nova ordem, também a política externa e, após 1880, a expansão e a administração colonial, exigiam conhecimentos específicos e treinamento que não eram ministrados pelas tradicionais faculdades de jurisprudência ${ }^{7}$. O que estava em jogo, portanto, era a formação de uma nova elite estatal.

Após a aposentadoria de Messedaglia, o curso entrou em declínio e o número de inscritos diminuiu. As exigências da política eram outras, e uma reforma no projeto se fazia cada vez mais necessária. Assim, no começo do século XX, o antigo curso complementar foi extinto e um novo ensino de administração colonial ocupou seu lugar. A expansão colonialista italiana no norte da África havia dado seus primeiros passos na Eritréia e na Somália. Era, entretanto, muito mais um sonho nacionalista e imperial do que uma realidade efetiva. De todo modo, sob forte inspiração das discussões que se realizavam na França, onde a administração colonial tornava-se cada vez mais importante e a educação, o treinamento e o recrutamento dos administradores era objeto de debate público, criou-se na Itália uma Scuola diplomatico-coloniale ${ }^{8}$.

A nova Scuola foi concebida como uma transformação do corso complementare. O decreto real no 514 , de 5 de dezembro de 1901, definia em seu artigo 1ำ que os objetivos da nova instituição eram

incrementar a cultura superior; preparar convenientemente os aspirantes às carreiras dependentes do Ministério dos Negócios Exteriores; e, em geral, promover a difusão dos conhecimentos científicos que melhor servem à imigração, ao comércio e à expansão pacífica da Itália no exterior (Regio Decreto, 1901:160).

Para cumprir esses objetivos, o mesmo decreto designou à nova Scuola professores de direito diplomático, consular e marítimo e história dos 
tratados; política da imigração e das colônias; política comercial e legislação alfandegária comparada; e geografia política e colonial (idem).

O fato de a Scuola ser um anexo da Facoltà giuridiche acarretou certa confusão, como se pode ver no debate parlamentar de 13 de maio de 1905. Interpelando o ministro da Instrução Pública, o senador Augusto Pierantoni (1840-1911) esclareceu que "a Scuola diplomatico-coloniale não existe e nunca existiu como instituto de estudos superiores autônomo" (Regno, 1905:2137). Segundo o senador, entretanto, a intervenção do Ministério havia desvirtuado a proposta inicial e colocado a Scuola à margem da lei e do decreto régio que a instituiu (idem). Outros senadores, como Vittorio Scialoja (1856-1933) e Giorgio Arcoleo (1848-1914), intervieram na discussão, afirmando que o principal problema estaria na resistência que a Facoltà giuridica apresentava à constituição da Scuola diplomatico-coloniale e reivindicando os fins práticos que haviam levado à sua criação (ididem: 2137-2138).

Mas as reclamações já eram inócuas e as decisões haviam sido tomadas. Um decreto régio de 23 de fevereiro de 1905 havia suspendido previamente novas inscrições na Scuola. Em sua resposta a Pierantoni, o ministro Leonardo Bianchi (1848-1927) ponderou que quando assumiu o cargo teve que decidir entre ocupar-se da Scuola ou deixá-la morrer. Para o ministro, o empreendimento já havia nascido sem vitalidade e rapidamente mostrou suas deficiências. Ao contrário das congêneres da Bélgica, Holanda, Inglaterra e França o estabelecimento italiano não havia sido útil à nação ${ }^{9}$. Daí que Bianchi não desejasse reviver a experiência: "ele não deseja fazer ressurgir um morto, não deseja dar novamente vida à defunta Scuola, porque, como biólogo, pode conceber a possibilidade de metempsicose, não de ressurreição", registraram as atas parlamentares (idem). O régio decreto no -609 , de 24 de novembro 1905, pôs fim à discussão encerrando definitivamente as atividades da Scuola.

\section{A FASCISTIZAÇÃO DAS CIÊNCIAS POLÍTICAS}

Nas duas primeiras décadas do século XX a única experiência de afirmação na Itália das Ciências Sociais e da Ciência Política como um conjunto disciplinar autônomo foi a do Istituto di Scienze Sociale Cesare Alfieri, sediado em Firenze. O Istituto teve origem na Scuola di scienze sociale, criada por Carlo Alfieri (1827-1897) em 1875, com o propósito de estabelecer um centro de altos estudos e de pesquisas avançadas 
voltado para a formação do pessoal dirigente necessário à nova vida nacional pós-unitária. Tratava-se de uma iniciativa privada, autônoma e independente do sistema universitário do Reino, da qual muito se orgulhavam as classes dirigentes florentinas (Rogari, 2004a:13). A partir de 1882, o diploma da Scuola foi equiparado ao diploma jurídico, para fins de concursos da administração central e, em 1887, para fins de ingresso na carreira diplomática. Em 1888, a Scuola foi transformada por decreto régio em Istituto di Scienze Sociale Cesare Alfieri (cf. Spreafico, 1964:206).

Em 1923, com a reforma da educação, que levou o nome de seu promotor, o ministro Giovanni Gentile, o Istituto Cesare Alfieri foi enquadrado na nova legislação fascista. Embora mantivesse o estatuto de uma Università libera, foi obrigado a prolongar para quatro anos a duração do curso, o que provocou com o passar do tempo uma queda substancial do número de inscritos. O efeito mais sentido, entretanto, foi a degradação dos estudos políticos e a multiplicação das disciplinas jurídicas, partilhadas com a Facoltà di Giurisprudenza, as quais chegaram a ser 14 de um total de 21 (Rogari, 2004:679). O predomínio dos estudos jurídicos no Istituto fez com que gradativamente perdesse força o ensino da ciência política, da ciência da administração, o estudo da filosofia política e das disciplinas de história do pensamento político contemporâneo e das instituições, que constituíam o fulcro do projeto original.

Essa não foi, contudo, a única iniciativa do novo regime fascista. Em março de 1924, Gentile fundou uma Scuola di scienze politiche na Università di Roma e criou uma comissão com o objetivo de apresentar uma proposta de ordenamento. Antonio Salandra, Umberto Ricci (1878-1957) e Gioacchino Volpe (1876-1971) faziam parte dessa comissão, os dois últimos alinhados com o governo fascista. A comissão chegou a uma conclusão unânime a respeito de "construir uma scuola com uma fisionomia bem distinta e nitidamente separada da Facoltà di Giurisprudenza" (apud Gentile, 2003:48). A presença de destacados liberais no corpo docente da nova Scuola expressava o desejo acalentado por Giovanni Gentile de reconduzir para o seio do movimento fascista os herdeiros intelectuais da Destra storica e de viabilizar seu programa de reforma escolar com o apoio destes (cf. D’Addio, 1993:342).

Os conflitos eram de se esperar, uma vez que na Facoltà era grande o número daqueles, entre os quais Mosca, que se opunham a Mussolini. 
A presença de liberais lecionando na Scuola motivou protestos por parte dos fascistas reunidos no jornal L'Impero, os quais exigiam a demissão de Salandra, Mosca e Ricci. Nas páginas desse jornal, Silvio Maurano protestava:

A Scuola Politica, assim como é pensada não responde minimamente às exigências em função das quais surgiu. Afortunadamente, não está em condições de dar uma orientação espiritual. Mas serve otimamente aos mestres de cultura do velho regime para desvalorizar a importância do Fascismo, fenômeno político e social de proporções e de dimensões ainda não avaliáveis (apud Gentile, 2003:51).

Os mesmos protestos podiam ser encontrados nos principais órgãos da imprensa fascista, como L'Idea Nazionale e Il Popolo d'Italia. À medida que o fascismo se constituía como um regime político, cresciam as pressões para a fascistização das universidades e, especialmente importante para tal, era o controle das faculdades de ciências políticas, entre as quais se destacava a de Roma. Um novo regime político estava surgindo e ele era incompatível com as antigas instituições e com a Scuola. Desde o final de 1923, o governo de Benito Mussolini vinha aplicando duros golpes ao regime político liberal. Primeiro, instituiu um exército próprio, institucionalizando as milícias voluntárias formadas pelos antigos membros das squadre d'azione. Em seguida, criou um parlamento paralelo, com a conversão do Gran Consiglio do fascismo, nomeado pelo próprio chefe do governo, em um órgão do Estado (ver Procacci, 2006:509).

As eleições de abril de 1924 marcaram, entretanto, um novo momento da conversão do governo fascista em um novo regime. O pleito foi levado a cabo de acordo com a nova lei eleitoral, a qual estabelecia que o partido que obtivesse o maior número de votos teria automaticamente dois terços das cadeiras na câmara (cf. Smith, 2005:438). A violência, a fraude e a ilegalidade deixaram sua marca nos resultados e a lista dos fascistas, chamada de listone, garantiu a maioria das cadeiras graças à nova fórmula eleitoral. Mas ao contrário do desejado por Mussolini, o governo sofreu importantes derrotas no norte da Itália e nas grandes cidades operárias. No dia 30 de maio, o deputado socialista Giacomo Matteotti (1885-1924) subiu à tribuna para denunciar a fraude eleitoral:

Vocês, deputados da maioria, neste momento confessaram que nenhum eleitor italiano se encontrou livre perante as urnas [murmúrios]. 
O eleitor sabia que se tivesse votado contra, seu voto seria anulado [murmúrios]. Isso não teria ocorrido se todos os cidadãos fossem livres (La Stampa, 31/5/1924, p. 1).

Dez dias depois, Matteotti foi raptado e assassinado. Seu corpo apareceu no dia 16 de junho em um descampado na cidade de Roma.

O envolvimento do governo de Mussolini com o rapto e o assassinato do deputado socialista era evidente e rapidamente desencadeou-se uma aguda crise institucional. Os parlamentares oposicionistas se retiraram da câmara e instalaram uma assembleia paralela, o chamado Aventino ${ }^{10}$. Mas a direção liberal e os moderados socialistas perderam a oportunidade de confrontar o governo nas ruas, dando tempo para Mussolini refazer suas forças. No dia 17 de junho, La Stampa noticiava que o comitê diretivo da seção romana do Partito Socialista Unitario, ao qual pertencia Matteotti,

ante as manifestações que aqui e acolá esporadicamente ocorrem, convida a massa operária a abster-se de tais manifestações, que poderiam dar lugar a especulações dos adversários, e mantém a confiança em que os órgãos dirigentes responsáveis procurarão organizar uma manifestação unânime e digna do Mártir. (La Stampa, 16/6/1924, p. 2).

Também Il Mondo exortava "trabalhadores romanos a conservarem uma atitude comportada e digna e a não se afastarem do trabalho. A pressão da opinião pública, potente e inexorável, conseguirá impor a luz, e que a justiça seja feita".

Livre para reagir, Mussolini desafiou a oposição em seu discurso parlamentar do dia 3 de janeiro de 1925. O pronunciamento foi o sinal para uma decidida ofensiva fascista que alterou profundamente a relação de forças. Afastada do povo e das ruas, a oposição liberal e reformista foi facilmente derrotada. Em seu discurso, o chefe de governo não escondeu a intenção de usar a força para derrotar rapidamente a oposição:

o governo é suficientemente forte para suprimir completa e definitivamente esta sedição do Aventino. (...) A Itália, senhores, quer a paz, quer a tranquilidade, quer a calma laboriosa. Esta tranquilidade, esta calma laboriosa nós a daremos com o amor, se possível, e com a força, se necessário (...). Estejam certos que nas quarenta e oito horas sucessivas a meu discurso, a situação estará esclarecida completamente (Mussolini, 1956:240). 
Bastaram dias para que a ordem fosse restabelecida. A partir de então teve início a rápida transformação do governo fascista em um novo regime político. No mesmo dia do discurso, os ministros liberais Alessandro Casati (1881-1955) e Gino Sarrocchi (1870-1950) e os fascistas moderados Alberto De Stefani (1879-1869) e Aldo Oviglio (1873-1942) pediram demissão do governo. A seguir, os parlamentares oposicionistas que haviam se reunido no Aventino foram expulsos da Câmara, os partidos imobilizados por uma nova lei das associações políticas, os antifascistas cassados e expulsos do serviço público, os prefeitos dos municípios substituídos por podestàs indicados e uma polícia política e um tribunal especial foram constituídos para espionar, acusar e julgar os opositores. Enfim, o regime político liberal foi derrubado golpe a golpe e um novo aparelho político assumiu seu lugar.

A timidez da oposição parlamentar e a conjuntura econômica favorável davam margem de manobra para essa transformação radical dentro da ordem capitalista. Superada rapidamente a crise do Aventino, o novo regime reuniu forças para consolidar um aparelho policial e repressivo, e para esmagar definitivamente a oposição. O fascismo encontrou na forma de um novo regime político uma estabilidade que seus opositores não esperavam. O impacto dessa nova situação nas instituições culturais e de ensino do reino da Itália se fizeram sentir rapidamente, e a oposição à presença dos liberais na Scuola tornou-se cada vez mais aguda.

Gentile, já havia se demitido do governo em junho de 1924, no rastro da crise do delitto Matteotti. Foi sucedido pelo já citado Alessandro Casati, amigo de Benedetto Croce, o qual no curto período em que ocupou o ministério da Instrução Pública - de 27 de junho de 1924 a 5 de janeiro de 1925 - deu prosseguimento ao projeto gentiliano da Scuola. Mas, como visto, Casati esteve entre aqueles que renunciaram após o discurso de Mussolini. Foi substituído pelo professor de história medieval da Facoltà di Lettere dell'Università di Roma, o deputado fascista Pietro Fedele (1873-1943). Entre os primeiros atos do novo ministro esteve a nomeação dos três primeiros professores da Scuola: Alfredo Rocco (1875-1935), para a cátedra de "Legislação econômica do trabalho"; Luigi Rossi (1867-1941), para a de "Direito público comparado"; e Gioacchino Volpe, para a de "História moderna". Todos os três fascistas. No ano acadêmico de 1924-1924, a Scuola ainda partilhou com a Facoltà di Giurisprudenza os professores Alfredo Codacci-Pisanelli (1861-1929), Antonio De Viti De Marco (1858-1943), Gaetano Mosca, Antonio Salandra, Giorgio Del Vecchio (1870-1970), Rodolfo Benini 
(1862-1956), Umberto Ricci (1879-1946) e Vittorio Emanuele Orlando (1860-1952) (D'Addio, 1993:351).

A nova Scuola, ainda marcada pelo ensino dos liberais, não tinha, porém, lugar em um regime fascista. A transformação da Scuola em Facoltà pelo novo ministro Pietro Fedele, com um decreto de 4 de setembro de 1925, foi vista, assim, como uma vitória dos fascistas integralistas. Em dezembro do mesmo ano, um decreto régio definiu o ordenamento da nova Facoltà e expôs seus objetivos: "promover a alta cultura econômica, política e social, e fornecer a preparação para as carreiras administrativa, diplomático-consular e colonial" (Regio Decreto, 1926:390). O decreto determinou o conjunto de disciplinas obrigatórias que deveriam ser cursadas. A lista delas fornece um retrato interessante do processo de institucionalização acadêmica da ciência política na Itália:

1. Filosofia do direito. 2. Instituições do direito privado italiano. 3. Direito público interno. 4. Direito público comparado. 5. Direito internacional público e privado. 6. Estatística metodológica. 7. Economia pura. 8. Legislação econômica e do trabalho. 9. Política e legislação financeira. 10. Política e estatística econômica. 11. Ciência política. 12. História política moderna. 13. História política colonial (Regio Decreto, 1926:390-391).

Comparando com os projetos anteriores, percebe-se que apesar do considerável número de disciplinas jurídicas, apareciam no programa disciplinas próprias do estudo da política, entre estas, pela primeira vez, a de "Ciência política". A reorganização da Facoltà implicou, também no afastamento de Orlando, Salandra, Codacci, Pisanelli, De Viti De Marco, Ricci e Mosca das atividades da Scuola, permanecendo estes exclusivamente na Facoltà di Giurisprudenza. A oposição liberal era, assim, acantonada, sua atividade acadêmica circunscrita e seus expoentes afastados da atividade formativa dos grupos dirigentes do novo regime.

O acidentado percurso da disciplina de "Ciência política" permite jogar luz sobre o complexo processo de reorganização institucional e sobre os efeitos do afastamento dos liberais da Facoltà di Scienze Politiche. Depois de criada pelo decreto, o conselho da Facoltà designou provisoriamente a cadeira de "Ciência política" a Volpe, o qual logo a seguir renunciou ao cargo, alegando suas muitas ocupações. A disciplina foi, então, assumida pelo economista Alberto De Stefani, o qual, 
embora fosse um fascista da primeira hora e recém-nomeado diretor da Facoltà, era visto com desconfiança pelos radicais (cf. D'Addio, 1993:369). Nos anos de 1925 e 1926, De Stefani organizou o curso com a participação de professores vindos de outras faculdades e destacadas personalidades do mundo fascista, como o conselheiro de Estado Domenico Barone (1878-1929), o ministro Luigi Federzoni (1878-1967), jornalista Roberto Davanzati (1880-1936) e os professores Robert Michels, Bernardino Varisco (1850-1933) e o próprio Volpe (cf. Gentile, 2003:55).

Com essa configuração, a disciplina passou a acolher conferências sobre os mais variados temas, principalmente aqueles relevantes para a política imediata, afastando-se consideravelmente do estudo científico da política advogado por outros professores, como Mosca. O desconforto proveniente de professores mais reticentes a um ensino diretamente engajado nos problemas políticos fez com que a disciplina se revelasse rapidamente um incômodo. Foi então que, sem oposição explícita, o novo estatuto da Università di Roma, de outubro de 1926, simplesmente suprimiu do catálogo de disciplinas a cadeira de "Ciência política". Oposição houve, entretanto, e proveniente de vários lados do espectro político, ao aumento considerável do número de disciplinas nas quais era ministrado o ensino jurídico (Regio Decreto, 1927:694) ${ }^{11}$.

A Facoltà di Scienze Politiche de Roma não foi a única inciativa do governo fascista nesse campo. Outras faculdades de ciências políticas foram criadas. Em Pavia, onde desde o século XIX havia uma forte tradição de estudos jurídicos e políticos, o estatuto da universidade promulgado em 1926 previa uma Facoltà di Scienze Politiche, que ofereceria um curso de quatro anos, os últimos dois dedicados ao ensino "político-diplomático, para os jovens que desejam dedicar-se particularmente às carreiras políticas", e "político-administrativo, para aqueles que desejam dedicar-se mais propriamente às carreiras públicas e administrativas" (Regio Decreto, 1926a:5577). Apesar da tradição paviana, as disciplinas oferecidas eram predominantemente jurídicas $^{12}$. Faculdades também foram criadas em Padova e Perugia e, em outros casos, cursos de láurea em ciências políticas passaram a fazer parte de várias faculdades jurídicas (cf. Spreafico, 1964:206).

O ponto alto da fascistização das ciências políticas na Itália foi a criação da Facoltà Fascista di Scienze Politiche, na Università di Perugia. 
Quando em julho de 1925, o reitor Edoardo Tommasone dirigiu-se a Roma para agradecer a Benito Mussolini pela inclusão do antigo Ateneo no sistema estatal de ensino superior e sua conversão na Regia Università di Perugia, ouviu de il duce: "A Università di Perugia deve ser a Università fascista" (apud Di Nucci, 2008:99). Após a declaração de Mussolini, as autoridades peruginas colocaram-se em movimento e convocaram o professor de filosofia do direito na Facoltà di giurisprudenza di Perugia, Sergio Panunzio (1886-1944), para dirigir o novo projeto. Proveniente das fileiras do sindicalismo revolucionário, Panunzio havia exercido grande influência sobre o pensamento de Mussolini e era um dos principais ideólogos do regime fascista. Era, assim, uma figura talhada para a nova missão.

No final de 1925, Panunzio já tinha preparado um projeto de construção de uma Scuola di studi fascisti com a finalidade de promover cursos de dois anos de duração destinados a formar jovens para as carreiras política, administrativa e sindical. O plano inicial foi aprovado por Mussolini que, no entanto, insistiu que se acrescentasse o ensino diplomático com a finalidade de formar cônsules e embaixadores para os serviços requisitados pelo regime fascista. O título fornecido ao final desses anos seria o de "doutor em disciplinas fascistas" (cf. Di Nucci, 2008:100).

A Scuola projetada por Panunzio tinha o propósito explícito de formar quadros político-administrativos capazes de substituir os antigos funcionários exonerados no processo de fascistização da máquina estatal (ibidem:101) ${ }^{13}$. Mas o projeto permaneceu no papel até novembro de 1927, quando um decreto real determinou: "Junto à Regia Università di Perugia é consentida a constituição de uma Facoltà fascista di scienze politiche" (Regio Decreto-Legge, 1927:4539). Um decreto de março de 1928 aprovou o estatuto da nova instituição, definindo seus objetivos, organização e desenho pedagógico, e um novo decreto, de dezembro do mesmo ano, reformulou os estatutos (Regio Decreto, 1928, 1928a). De acordo com esse último decreto, a nova faculdade teria o objetivo de "promover o conhecimento e a consciência do fascismo e de preparar os fascistas para as carreiras: Administrativa, Sindical-corporativa, Consular-diplomática, Colonial e Jornalística" (Regio Decreto, 1928a:6251).

O curso da nova faculdade devia ter a duração de quatro anos e conceder, ao seu término, um diploma de láurea em ciência política. Um con- 
junto de 28 disciplinas deviam ser oferecidas, sendo as primeiras "História e doutrina geral do fascismo", "Sistema da legislação fascista", "Direito corporativo"; na segunda versão do decreto, foi eliminada a disciplina de "Política sindical e corporativa" presente no elenco da primeira versão. Predominavam na grade curricular as disciplinas de história e direito. A presença dos estudos políticos strictu sensu era reduzidíssima e se limitava às disciplinas de "História das doutrinas políticas" e "História da política moderna e contemporânea" (Regio Decreto, 1928a).

Poucos meses depois do início do funcionamento da nova instituição, Mussolini recebeu uma comitiva, chefiada por Panunzio, a qual apresentou a nova Facoltà ao chefe do governo. Em seu discurso, Panunzio confirmou que a Facoltà era integrante da "revolução fascista". O número de estudantes matriculados chegava a 96 e os dirigentes da instituição estimavam que nos anos seguintes esse número seria triplicado. Mas o discurso não enaltecia a capacidade da nova instituição para formar os quadros estatais desejados e sim seu engajamento na luta ideológica. Panunzio, por exemplo, destacou:

é com profunda satisfação que pude notar através do desenvolvimento dos cursos de ensino e dos exames finais que, finalmente, o Fascismo entrou plenamente na Università. Cito apenas um caso: ontem em um exame de história e doutrina geral do Fascismo, havia esta precisa e seca pergunta: “O 3 de janeiro de 1925", a breve resposta: “Duce!" ( $L a$ Stampa, 14/7/1928, p. 2).

E concluiu anunciando aquele que considerava ser o principal problema do fascismo, conquistar a consciência das pessoas, "o fascismo não apenas nas coisas e nas instituições, mas nas almas". Panunzio explicava a Mussolini que era nessa batalha pelas almas que a nova Facoltà se provava e justificava: "temos podido constatar com alegria que nos jovens, que vós portastes à cena da vida italiana, a moral é altíssima e as velhas ideias políticas e sociais estão mortas e não expandem a luz viva das novas Ideias do Fascismo que vosso gênio político inculcou" (idem). O chefe do governo, por sua vez, respondeu que estava muito satisfeito com os resultados obtidos, que a Universtità di Perugia deveria ser "o fulcro do novo ordenamento da cultura universitária italiana" e que os títulos da Facoltà deveriam ter, nos próximos concursos, um coeficiente de preferência para privilegiar o ingresso dos fascistas na carreira estatal, proposta que, entretanto, nunca foi levada a cabo (idem, cf. também Gentile, 2003:65). 
Por iniciativa de Panunzio, a Facoltà abrigou destacados professores, muitos dos quais haviam passado pelas fileiras do sindicalismo revolucionário, como Angelo Oliviero Olivetti (1874-1931), Paolo Orano (1875-1945) e Robert Michels, assim como os antigos nacionalistas Maurizio Maraviglia (1878-1955) e Francesco Coppola (1878-1957), além de jovens professores como Carlo Curcio (1898-1971) e Giuseppe Chiarelli (1904-1978). Vários deles escreveram para a Collana di Studi Fascisti, a qual chegou a publicar doze volumes. Concebida por Panunzio para ser a síntese da nova vida cultural italiana, a instituição se mostrou bastante ampla para acolher docentes sem vínculos com o fascismo, como Alberto Maria Ghisalberti (1894-1986), Federico Chabod (1901-1960), e Luigi del Pane (1903-1979), ainda que estes fossem mantidos sob estrito controle.

Mas apesar de sua envergadura, ou talvez devido a ela, o projeto da Facoltà fascista fracassou. Panunzio sempre havia dado muita ênfase à necessidade de uma coerente doutrina fascista e por essa razão seu estabelecimento tinha grande importância na avaliação dos resultados de seu empenho. Com o passar dos anos, o antigo sindicalista revolucionário, consternado, passou a considerar que os esforços levados a cabo em Perugia não tinham sido suficientes para a criação de uma doutrina fascista definitiva (cf. Roberts, 1979:286). Os resultados obtidos na formação de quadros fascistas foi ainda mais decepcionante. $\mathrm{Na}$ opinião de estudantes pertencentes aos Gruppi Universitari Fascisti (GUF) de Perugia, os antigos quadros da burocracia estatal boicotavam o ingresso de jovens fascistas provenientes da Facoltà (cf. La Rovere, 1999:467). Mas a explicação destes não é plenamente satisfatória e os debates realizados nas décadas seguintes pelos fascistas acrescentaram outras razões de caráter estrutural.

\section{CONCLUSÃO}

As reformas do ensino superior levadas a cabo pelos ministros Cesare Maria De Vecchi (1884-1959), em junho de 1935, e Giuseppe Bottai (1895-1959), em setembro de 1938, não produziram profundas alterações no dispositivo acadêmico e nas faculdades de ciências políticas. A reforma De Vecchi transformou em obrigatórias para a obtenção da láurea em ciência política disciplinas que já eram ministradas em universidades como a de Perugia, tais como "Direito corporativo" e "História e doutrina do fascismo" (Regio Decreto, 1935:5564). No mesmo sentido, os estatutos do Istituto Cesare Alfieri e da Università Cattolica 
del "Sacro Cuore" di Milano foram modificados e tais disciplinas foram introduzidas no currículo (Regio Decreto, 1936a:3572; 1936:3462).

A reforma Bottai, por sua vez, pode ser considerada o ápice da fascistização do sistema de ensino. Na Carta della Scuola aprovada pelo Gran consiglio del Fascismo em 15 de fevereiro de 1939, escola e fascismo finalmente encontravam sua síntese:

A unidade moral, política e econômica da Nação italiana, que se realiza integralmente no Estado fascista, a escola, fundamento primeiro de solidariedade de todas as formas sociais, da família à Corporação e ao Partido, forma a consciência humana e política das novas gerações $\left(\right.$ Carta, 1939:1294) ${ }^{14}$.

Mas a reforma não trouxe grandes modificações para as Facoltà di Scienze Politiche, as quais continuaram sem afirmar uma identidade própria e incapazes de formar a nova classe dirigente que o fascismo desejava.

Seus limites ficaram claros no seminário interuniversitário realizado em 1942 em Firenze. As acusações mais fortes vieram do sociólogo Camillo Pellizzi, professor de História e Doutrina do Fascismo na Università di Messina. Segundo Pellizzi, nos últimos vinte anos a vida política italiana havia sido dirigida por "um grandíssimo Capo e, ao redor dele, poucas personalidades eminentes isoladas". Faltava, entretanto, o "embrião daquilo que, impropriamente talvez, muitos esperam afirmar a necessidade de uma 'classe' dirigente" (apud Gentile, 2003:76). As faculdades de ciências políticas existentes não haviam se tornado um espaço para a formação dessa nova classe dirigente, acreditava Pellizzi. Em sua maioria, os alunos matriculados estavam apenas em busca de um segundo título superior sem muito esforço que lhes permitisse disputar cargos públicos em melhores condições. A conclusão de Pellizzi era para muitos desalentadora: "os resultados das atuais Facoltà são geralmente nulos e frequentemente negativos, na medida em que criam a presunção de capacidade e de competência, que, na maioria dos casos, não corresponde a nenhuma realidade" (idem).

De fato, a contribuição dos cursos de ciências políticas para a formação dos quadros dirigentes do regime fascista foi muito pequena. No corpo do diretório nacional do Partito Nazionale Fascista (PNF), durante 
todo o período de sua existência, de 1922 à queda do regime, nenhum tinha título superior de ciência política e apenas quatro possuíam título em "jurisprudência e ciência política". Dos secretários de federações, somente cinco eram titulados em ciência política e entre os membros das câmaras dos fasci e das corporações os portadores desse título eram apenas 14 , totalizando $2,4 \%$ do total. Comparados com o peso dos portadores de títulos superiores em Giurisprudenza, esses números parecem ainda menores: mais de $56 \%$ dos membros do diretório nacional do PNF possuíam um título em direito (Di Nucci, 2008:112; Gentile, 2003:74).

O programa pedagógico de Muratori e Romagnosi esteve longe de ser realizado pelo fascismo. Apesar de terem sido várias as propostas de construção de cursos, escolas e faculdades de ciências políticas ao longo do século XIX e da primeira metade do século XX, cujo principal objetivo fosse a formação de quadros dirigentes para o aparelho estatal, todas as iniciativas fracassaram. Os fascistas levaram esse programa muito além das experiências anteriores, mas não se pode dizer que tenham atingido seus objetivos. Uma das razões para tal pode ser o caráter eclético das chamadas "ciências políticas". Ao fazerem uso da expressão no plural as autoridades universitárias manifestavam uma concepção segundo a qual as instituições de ensino superior especializadas na formação do pessoal estatal dirigente reuniriam o variado conjunto dos conhecimentos necessários para o estudo da política. Disciplinas de história, direito e economia ocupavam lugar de destaque nos currículos. A política, entretanto, era sempre um objeto desse conhecimento histórico, jurídico ou econômico e nunca um campo de reflexão autônomo.

Sem afirmar-se de maneira autônoma as scienze politiche tinham dificuldades de se justificar perante os cursos jurídicos. Não foram poucas as resistências que se organizaram a partir das próprias Facoltà giuridiche contra a pretensão de suas vizinhas de scienze politiche. As razões práticas eram variadas e iam desde a incômoda obrigação de o corpo docente oferecer disciplinas para os estudantes dessas ciências, até a mesquinha disputa por empregos públicos. O fato de os portadores de diplomas em estudos jurídicos ou jurisprudência terem acesso frequentemente aos mesmos cargos públicos que aqueles que haviam obtido uma láurea em scienze politiche tornava ainda mais aguda essa disputa e mais frágil a posição de uma Facoltà especializada. 
Mas além dessas razões de ordem prática havia outras de ordem intelectual. A longa e sólida tradição de estudos jurídicos na Itália exercia sua hegemonia sobre o ambiente cultural da península e, particularmente, no Norte. Essa hegemonia se refletia não apenas nas disciplinas que conformavam os currículos das Facoltà di scienze politiche, como também no próprio corpo docente dessas instituições, a maior parte do qual era proveniente das Facoltà giuridiche. O formalismo próprio dos estudos jurídicos imprimiu sua marca nos estudos políticos, impedindo o desenvolvimento destes nas instituições que deveriam sediá-los. Duas exceções merecem ser destacadas: o corso di sociologia politica, no qual Robert Michels (1927) reuniu suas lições na Facoltà di Scienze Politiche da Università di Roma, e as Lezioni di storia delle istituzioni e delle dottrine politiche, de Gaetano Mosca (1932), resultado de suas aulas na mesma Facoltà.

As exceções, entretanto, confirmam a regra. O estudo das elites produzido por Robert Michels e a investigação das instituições e ideias políticas levada a cabo por Gaetano Mosca caracterizam-se por guardar distância dos estudos jurídicos predominantes e por procurar na sociologia e na historiografia a base para suas pesquisas. Embora expressassem uma rica tradição de estudos políticos que poderia remontar até mesmo a Machiavelli, os trabalhos desses autores continuaram a ser exceções e de toda maneira não constituíram um corpo teórico sobre o qual pudesse se afirmar de modo autônomo o estudo e o ensino da política ${ }^{15}$. A ciência política italiana continuaria sem uma sede acadêmica própria e se desenvolveria na primeira metade do século XX fora das instituições universitárias que teriam sido construídas para supostamente abrigá-las.

Luigi Graziano insistiu na distinção entre a ciência política da primeira metade do século XX e aquela que teve lugar depois da Segunda Guerra Mundial, quando finalmente conseguiu se afirmar como uma disciplina autônoma. Argumentou que essas diferenças se deveram à interação de quatro fatores: a) o esforço consciente de alguns autores, como Norberto Bobbio (1909-20014), Bruno Leoni (1913-1967) e Giovanni Sartori (1924-), para resgatar a ciência política do ostracismo e afirmar a autonomia do campo disciplinar; b) as grandes mudanças sociais, políticas e econômicas que ocorreram na Itália do pós-guerra; c) o impacto da ciência política norte-americana e do behavioralismo; e d) as mudanças no sistema universitário italiano (Graziano, 1991). 


\section{Alvaro Bianchi}

Esses fatores teriam contribuído para que, a partir de meados dos anos 1950, a ciência política italiana avançasse em seu processo de consolidação como uma disciplina autônoma. Bobbio, Leoni e Sartori haviam começado suas carreiras no âmbito da filosofia ou da filosofia do direito e não era difícil distinguir neles certas reverberações daquela antiga tradição do pensamento político da península. Mas a nova ciência política que ajudaram a criar afastou-se rapidamente dessa tradição, aproximando-se, velozmente dos métodos e das abordagens teóricas da ciência política norte-americana. Mesmo assim, o percurso da institucionalização dessa ciência não deixou de ser acidentado e apenas em meados da década de 1980 surgiram os primeiros programas de doutorado em Ciência Política. Também aqui uma história política da ciência política teria algo a dizer.

(Recebido para publicação 6 de junho de 2015)

(Reapresentado em março de 2016)

(Aprovado para publicação 15 de agosto de 2016) 


\section{A Difícil Institucionalização da Ciência Política Italiana}

\section{NOTAS}

1. Sobre a história do pensamento e da ciência política italiana na primeira metade do século XX ver, dentre outros Albertoni (1985), Bedeschi (2002), Bobbio (2002), Palano (2005), Perticone (1950) e Sola (1984; 1990; 1992).

2. Rao (1996) constatou que ao contrário de seus congêneres, o Istituto Nazionale della Repubblica Napoletana, não seguiu tão de perto o modelo francês e não criou uma seção de scienze politiche ou scienze morali e politiche.

3. Cabe lembrar que nos séculos imediatamente anteriores à queda e ao saque de Roma (1527), momento que marca o fim do sonho acalentado por Machiavelli e por tantos outros de "livrar a Itália das mãos dos bárbaros", prosperou na península um discurso político de defesa da liberdade que se organizou em torno das ideias de autodeterminação, autonomia e autogoverno (Skinner, 1999). Esse discurso permanecerá adormecido em boa parte dos séculos XVI e XVII e retornará em meados do século XVIII com o renascer da ideia de Itália.

4. Frequentaram as scuole de Romagnosi expoentes do jacobinismo italiano, como Giuseppe Ferrari (1811-1876) e Carlo Cattaneo (1801-1869), mas também clericais reacionários como Cesare Cantù (1804-1895).

5. O fracasso da divisão em duas faculdades é discutido por Villari (1902), D'Addio (2003) e Fois (1991).

6. Protonotari foi o fundador e diretor da importante revista Nuova Antologia; Saredo foi senador do Reino (1890-1892); Palma é reconhecido como um dos maiores constitucionalistas italianos da segunda metade do século XIX; e Salandra foi senador e presidente do conselho de ministros entre 1914 e 1916 e, nessa condição, foi responsável pelas negociações secretas que implicaram no pacto de Londres e na entrada da Itália na guerra ao lado da Entente.

7. Em 1880, a Itália estabeleceu sua primeira colônia no norte da África.

8. Ver, p. ex. os comentários de Villari (1902). Sobre o ensino, treinamento e recrutamento dos administradores coloniais na França, ver Boutmy (1895). Boutmy foi fundador da École Libre des Sciences Politiques francesa e publicou em 1897 uma história dessa escola que muito influenciou Villari (Boutmy e Vinet, 1897).

9. Pierantoni colocou o dedo na ferida, insinuando que o ministro comparava o incomparável: "os institutos dos quais falou o ministro pertencem a nações como a Inglaterra e a França, que têm vastas possessões coloniais" (Regno, 1905:2138). As colônias italianas, como se sabe, eram de muito menor extensão, assim como as exigências reais de uma administração colonial.

10. Tratava-se de uma referência à história da Roma antiga quando o povo se retirou da cidade em protesto contra a opressão dos patrícios e ocupou a colina que tem esse nome.

11. O leque de disciplinas apresentadas era muito maior, chegando a 28 disciplinas, mas o estatuto não as classificava entre obrigatórias e opcionais. As disciplinas vinculadas aos estudos políticos que permaneceram no currículo eram: "Política e estatística econômica", "Política e legislação financeira", "História política moderna”, "História das colônias e política colonial", "História dos tratados e das relações internacionais" e "Doutrina geral do Estado" (Regio Decreto, 1927:694). 


\section{Alvaro Bianchi}

12. A Facoltà de Pavia sediava as disciplinas de "1. História das instituições políticas; 2. Instituições de direito comercial e industrial; 3 . Instituições de direito penal; 4. Ordenamentos dos Estados modernos; 5. Diplomacia e História dos tratados; 6. Geografia política e econômica; 7. Doutrinas políticas modernas; 8. Direito internacional privado; 9. Direito internacional público; 10. Política econômica dos Estados modernos; 11. Instituições da previdência e da poupança; 12. Economia e legislação bancária; 13. Legislação social; 14. Política e legislação colonial; 15. Ciência da administração". A Facoltà ainda utilizava disciplinas da Facoltà di Giurisprudenza, tais como "Instituições do direito civil", "Economia politica", "Estatística e demografia”, "Direito constitucional", "História do direito romano", "Filosofia do direito", "Direito eclesiástico", "Ciência das finanças e direito financeiro" e "Direito administrativo"; além de uma disciplina da Facoltà di Lettere: "História moderna" (Regio Decreto, 1926a:5577).

13. Em 24 de dezembro de 1925, foi promulgada a lei no 2.300 , a qual previa a possibilidade de "dispensar do serviço (...) os funcionários, empregados e agentes de todas as ordens e graus civis e militares (...) que por razão de manifestação dentro ou fora de seus cargos não dão plena garantia de um fiel cumprimento do próprio dever ou se coloquem em condições de incompatibilidade com as diretivas políticas gerais do governo" (Legge no 2.300, 24/12/1925. Dispensa dal servizio dei funzionari dello Stato, 1926:11). A nova lei permitiu expulsar do corpo de funcionários aqueles que eram suspeitos de se oporem ao regime.

14. Na nova ordem fascista, a "idade escolar" e a "idade política" passavam a coincidir e a participação dos estudantes do ensino médio na Gioventù Italiana del Littorio (GIL) era obrigatória, assim como a dos estudantes universitários nos Gruppi Universitari Fascisti (GUF) (Carta, 1939:1294). Sobre os GUF ver La Rovere (1999).

15. Sobre a herança machiaveliana nos estudos políticos italianos ver Medici (1990). 


\section{A Difícil Institucionalização da Ciência Política Italiana}

\section{REFERÊNCIAS BIBLIOGRÁFICAS}

ALBERTONI, Ettore A. (1985), Storia delle Dottrine Politiche in Italia. Milão, Mondadori.

BEDESCHI, Giuseppe. (2002), La Fabbrica delle Ideologie: Il Pensiero Político nell'Italia del Novecento. Bari, Laterza.

BOBBIO, Norberto. (2002), Ensaios sobre Ciência Política na Itália. Brasília, UnB; São Paulo, Imprensa Oficial do Estado.

BONGHI, Ruggero. (1875), "Regolamento della Facoltà di Giurisprudenza". Gazzetta Ufficiale dell Regno d'Italia, no 268, 17 de novembro, pp. 7078-7079.

BOUTMY, Émile. (1895), Le Recrutement des Administrateurs Coloniaux. Paris, Armand Collin.

; VINET, Roger. (1897), L'École Libre des Sciences Politiques (1871-1897). Paris, Chamerot et Renouard.

COSTA, Paolo. (1831), Discorsi di Paolo Costa intorno al Governo Constituzionale per Istruzione di quelli che non sono Versati nelle Scienze Politiche. Bologna, Baduel.

D'ADDIO, Mauro. (1993), “Gaetano Mosca e l'Istituzione della Facoltà Romana di Scienze Politiche". Il Politico-Rivista Italiana di Scienzi Politiche, vol. 2, no 166, pp. 329-373.

. (2003), "Le Origine della Facoltà Romana di Scienze Politiche", in F. Lanchester (org.), Passato e Presente delle Facoltà di Scienze Politiche. Milano, Giuffrè, pp. 25-44.

DI NUCCI, Loreto. (2008), Nel Cantiere dello Stato Fascista. Roma, Carocci.

FOIS, Giuseppina. (1991), “Per una Storia della Facoltà di Giurisprudenza: Le Due Lauree della Riforma Matteucci. Annali dell'Istituto Storico Italo-germanico in Trento, vol. XVII, pp. 573-577.

GENTILE, Emilio. (2003), "La Facoltà di Scienze Politiche nel Periodo Fascista", in F. Lanchester (org.), Passato e Presente delle Facoltà di Scienze Politiche. Milano, Giuffrè, pp. $45-85$.

GRAZIANO, Luigi. (1991), “The Development and Institutionalization of Political Science in Italy", in D. Easton; J. G. Gunnell; L. Graziano (eds.), The Development of Political Science: A Comparative Survey. London, Routledge, pp. 127-146.

LA ROVERE, Luca. (1999), "Fascist Groups in Italian Universities: An Organization at the Service of the Totalitarian State". Journal of Contemporary History, vol. 34, no 3, pp. 457-475.

MEDICI, Rita. (1990), La Metafora Machiavelli: Mosca, Pareto, Michels e Gramsci. Modena, Muchi.

MESSEDAGLIA, Angelo. (1869), “L'Insegnamento della Giurisprudenza nelle Universitá del Regno". Nuova Antologia, pp. 576-595.

(1880), L'Insegnamento Politico-amministrativo: Discorso d'Inaugurazione al Corso Complementare di Scienze Economico-amministrative presso la Facoltá di Giurisprudenza. Roma, Giuseppe Civelli.

MICHELS, Robert. (1927), Corso di Sociologia Politica. Milano, S. A. Instituto Editoriale Scientifico. 


\section{Alvaro Bianchi}

MOSCA, Gaetano. (1932), Lezioni di Storia delle Instituzionie delle Dottrine Politiche. Roma, Castellani.

MURATORI, Lodovico Antonio. (1749), Della Pubblica Felicità, Oggetto de' Buoni Prìncipi. Luca, s.e.

MUSSOLINI, Benito. (1956), Opera Omnia (14 giugno 1924-4 novembre 1925): A Cura di Eduardo e Diolio Susmel. Firenze, La Fenice.

PALANO, Damiano. (2005), Geometrie del Potere: Materiali per la Storia della Scienza Política Italiana. Milano, Vita e Pensiero.

PEPE, Luigi. (1996), “L'Istituto Nazionale della Repubblica Romana”. Mélanges de l'Ecole Française de Rome. Italie et Méditerranée, vol. 108, no 2, pp. 703-730.

PERTICONE, Giacomo. (1950), "Political Science in Italy", in Contemporary Political Science: A Survey of Methods, Research and Teaching. Paris, Unesco, pp. 249-261.

PROCACCI, Giuliano. (2006), Storia degli Italiani. Bari, Laterza.

RAO, Anna Maria. (1996), “L’Istituto Nazionale della Repubblica Napoletana”. Mélanges de l'Ecole Française de Rome. Italie et Méditerranée, vol. 108, no 2, pp. 765-798.

ROBERTS, David D. (1979), The Syndicalist Tradition and Italian Fascism. Manchester, Manchester University.

ROGARI, Sandro. (2004a), "Gli anni dell'Istituto di Studi Superiori Pratici e di Perfezionamento", in S. Rogari (ed.), L'Università degli Studi di Firenze fra Instituzionie Cultura nel Decennale della Scomparsa di Giovanni Spadolini: Atti del Convegno di Studi (Firenze, 11-12 Ottobre 2004). Firenze, Firenze University, pp. 13-17.

ROGARI, Sandro. (2004b), "Il ‘Cesare Alfieri' da Istituto a Facoltà di Scienze Politiche", in VVAA. L'Università Degli Studi di Firenze 1924-2004. Firenze, Olschki, pp. 677-739.

ROMAGNOSI, Giandomenico. (1832), Dell'indole e dei Fattori dell Inicivilimento com Esempio del suo Risorgimento in Italia. Milano, Annali Universali della Scienza e dell'Industria.

. (1839), Principi Fondamentali di Diritto Amministrativo onde Tesserne le Instituzioni. 4a ed. Prato, Tipografia Guasti.

. (1850), La Scienze delle Constituzioni: Opera Postuma. Firenzi, ASpesse Degli Editori.

SKINNER, Quentin. (1999), Liberdade antes do Liberalismo. São Paulo, Unesp.

SMITH, Denis Mack. (2005), Storia d'Italia dal 1861 al 1997. 4a ed. Bari, Laterza.

SOLA, Giorgio. (1984), “Scienza e Teoria nei Padri Fondatori della Scienza Politica Italiana". Quaderni Fondazione Feltrinelli, no 29, pp. 407-440.

. (1990), “La Scienza Politica Italiana dall’Unítà al Fascismo”, in S. R. Ghibaudi; F. Barcia (orgs.), Studi Politici in Onore di Luigi Firpo. Milano, Angeli, pp. 189-207, vol. IV.

. (1992), "La Scienza Politica Italiana di Fronte al Fascismo", in A. L. del Grosso (org.), Democrazia e Monocrazia in Europa nella Prima Metà del Novecento. Firenze, Centro Editoriale Toscano, pp. 7-117.

SPREAFICO, Alberto. (1964), “Studi Politici e Scienza Politica in Italia”. Annuario Politico Italiano, Milano, pp. 204-230. 


\section{A Difícil Institucionalização da Ciência Política Italiana}

VICO, Giambattista. (2005), Opere. Milano, Arlando Mondadori.

VILLARI, Pasquale. (1902), "Le Scuole di Scienza Sociale e le Facoltà Giuridiche”. Nuova Antologia, vol. 181, pp. 404-419.

\section{Outras Fontes}

BOLLETTINO delle Leggi della Repubblica Italiana: Dalla Costituzione Proclamata nei Comizi in Lione al 31 Dicembre 1802. (1803), vol. I, pp. 1-20.

CARTA della Scuola. (1939), Gazzetta Ufficiale del Regno d'Italia, no 61, 13 de março, pp. 1294-1298.

LEGGE, n. 2300, 24 dicembre 1925. Dispensa dal servizio dei funzionari dello Stato. Gazzetta Ufficiale del Regno d'Italia n. 2, p. 11, 4 gen. 1926.

REGIO DECRETO, n. 514, 5 dicembre 1901. Gazzetta Ufficiale del Regno d'Italia, vol. 308, pp. 6064-6065, 30 dic. 1901.

REGIO DECRETO, n. 2489, 27 dicembre 1925. Ordinamento della facoltà di scienze politiche della Regia Università di Roma. Gazzetta Ufficiale del Regno d'Italia, n. 21, p. 390-392, 27 gen. 1926.

REGIO DECRETO, n. 2130, 14 ottobre 1926. Approvazione dello statuto dell Regia Università di Pavia. Gazzetta Ufficiale del Regno d'Italia, n. 297, p. 5574-5586, 27 dic. 1926a.

REGIO DECRETO 14 ottobre 1926, n. 2319. Approvazione dello statuto della Regia Università di Roma. Gazzetta Ufficiale del Regno d'Italia, n. 38, p. 690-714, 16 feb. 1927.

REGIO DECRETO, n. 583, 15 marzo 1928. Approvazione dello statuto della Facoltà fascista di scienze politiche presso la Regia Università di Perugia. Gazzetta Ufficiale del Regno d'Italia, n. 80, p. 1420-1422, 4 abr. 1928.

REGIO DECRETO, n. 2831, 25 ottobre 1928. Approvazione del nuovo statuto della Facoltà fascista di scienze politiche presso la Regia Università di Perugia. Gazzetta Ufficiale del Regno d'Italia, n. 300, p. 6250-6253, 27 dic. 1928a.

REGIO DECRETO, n. 2044, 28 novembre 1935-XIV. Norme relative agli insegnamenti che debbono essere impartiti nelle Università e negli Istituti superiori. Gazzetta Ufficiale del Regno d'Italia, n. 284, p. 5563-5573, 6 dic. 1935.

REGIO DECRETO, n. 2088, 1o ottobre 1936-XIV. Modificazioni allo statuto del Reale Istituto superiore di scienze sociali e politiche "Cesare Alfleri" di Firenze. Gazzetta Ufficiale del Regno d'Italia, n. 279, p. 3461-3463, 2 dic. 1936.

REGIO DECRETO, n. 2066, 16 ottobre 1936-XIV. Approvazione dello statuto della libera Universita cattolica del "Sacro Cuore" di Milano. Gazzetta Ufficiale del Regno d'Italia, n. 286, p. $3567-3577,10$ dic. 1936 a.

REGIO DECRETO-LEGGE, n. 2105, 23 ottobre 1927. Disposizioni per l'istruzione superiore. Gazzetta Ufficiale del Regno d'Italia, n. 271, p. 4539-4542, 23 nov. 1927. 


\section{RESUMO}

A Difícil Institucionalização da Ciência Política na Itália: De Muratori a Mussolini

Embora existisse uma longa tradição nacional de pensamento político na Itália, a ciência política desse país enfrentou dificuldades para se institucionalizar. As primeiras tentativas datam do século XVIII, mas foi só na segunda metade do século XX que ela se transformou em uma disciplina autônoma. O presente artigo argumenta que a forte associação da ciência política com o processo de construção do Estado nacional italiano e com o ensino do direito foram as causas principais de sua lenta institucionalização. Metodologicamente, busca-se reconstruir uma história política da ciência política, ressaltando contextualmente o debate da época e restabelecendo a legislação pertinente à constituição de faculdades, escolas e cursos de ciência política.

Palavras-chave: história da Ciência Política; Antonio Muratori; Benito Mussolini; fascismo; Itália

\section{ABSTRACT}

The Complex Path to Institutionalizing Political Science in Italy: From Muratori to Mussolini

Despite the existence of a long national tradition of political thought in Italy, the path to institutionalizing political science in the country was riddled with difficulty. Although initial attempts date back to the eighteenth century, it was only in the second half of the twentieth century that the discipline was transformed into a subject in its own right. This article argues that the strong associations between political science and the teaching of law, as well as with the process of constructing the Italian national government, were the main reasons behind its slow institutionalization. In terms of methodology, the article seeks to reconstruct a political history of political science, contextually highlighting the debate of the time and reestablishing the legislation related to the constitution of political science faculties, schools and courses.

Keywords: history of Political Science; Antonio Muratori; Benito Mussolini; fascism; Italy 


\section{RÉSUMÉ}

La Difficile Institutionnalisation de la Science Politique en Italie: De Muratori à Mussolini

Bien qu'il existe une longue tradition nationale de la pensée politique en Italie, la science politique de ce pays a affronté un certain nombre de difficultés sur le chemin de son institutionnalisation. Les premières tentatives datent du

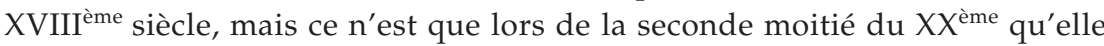
deviendra une discipline autonome. Le présent article défend l'idée selon laquelle la forte association entre la science politique, la construction de l'État national italien et l'enseignement du droit a constitué la principale cause de sa lente institutionnalisation. Du point de vue méthodologique, on cherchera à reconstruire une histoire politique de la science homonyme, à contextualiser les débats de l'époque et à analyser la législation afférente à la constitution de facultés, d'écoles et de cursus de sciences politiques.

Mots-clés: histoire des Sciences Politiques; Antonio Muratori; Benito Mussolini; fascisme; Italie

\section{RESUMEN}

La Difícil Institucionalización de la Ciencia Política en Italia: De Muratori a Mussolini

Aunque había una larga tradición nacional de pensamiento político en Italia, la ciencia política de aquel país tuvo dificultades para institucionalizarse. Los primeros intentos datan del siglo XVIII, pero solo en la segunda mitad del siglo XX se convirtió en una disciplina autónoma. El presente artículo plantea que la fuerte asociación entre la ciencia política y el proceso de construcción del Estado nacional italiano y la enseñanza del derecho fueron las principales causas de su lenta institucionalización. En términos metodológicos, se trata de reconstruir una historia política de la ciencia política, contextualizando el debate de la época y restableciendo la legislación pertinente a la constitución de facultades, escuelas y cursos de ciencia política.

Palabras clave: historia de la Ciencia Política; Antonio Muratori; Benito Mussolini; fascismo; Italia 